\title{
Flow transitions and flow localization in large-strain deformation of magnesium alloy
}

\author{
Dinakar Sagapuram ${ }^{\mathrm{a}, \mathrm{d}, \mathrm{e}}$, Mert Efe ${ }^{\mathrm{b}}$, Kevin P. Trumble ${ }^{\mathrm{c}, \mathrm{d}, *}$, Srinivasan Chandrasekara,d \\ ${ }^{a}$ School of Industrial Engineering, Purdue University, West Lafayette, IN 47907, USA \\ ${ }^{b}$ Department of Metallurgical and Materials Engineering, METU, Ankara, Turkey \\ ${ }^{c}$ School of Materials Engineering, Purdue University, West Lafayette, IN 47907, USA \\ ${ }^{d}$ Center for Materials Processing and Tribology, Purdue University, West Lafayette, IN 47907, USA \\ ${ }^{e}$ Currently at Department of Industrial and Systems Engineering, Texas A $6 M$ University, College Station, \\ $T X$ 7r843, USA
}

\begin{abstract}
Understanding transitions from homogeneous to localized flow, and mechanisms underlying flow localization, is of paramount importance for deformation processing of magnesium. In this study, a shear-based deformation method is utilized for imposing large strains $(\sim 1)$, under controllable strain rates $\left(10-10^{5} / \mathrm{s}\right)$ and temperatures $\left(80-300{ }^{\circ} \mathrm{C}\right)$, in order to examine flow patterns in a magnesium alloy. Based on microstructure characterization, deformation twinning is suggested to contribute to the localized flow at temperatures below $200{ }^{\circ} \mathrm{C}$ and at low strain rates. The transition from the localized to homogeneous flow with increasing temperature is due to reduction in twinning activity, and enhanced strain-rate sensitivity. At constant temperature, an increase in the strain rate decreases the propensity for flow localization. A model is presented for characterizing the maximum uniform strain as a function of temperature and deformation state (simple shear, plane-strain compression). The model incorporates temperature-sensitive microstructural changes and flow properties of magnesium into a classical framework to capture the flow localization phenomena at low temperatures and strain rates.
\end{abstract}

Keywords:

Magnesium alloys, Bulk deformation, Thermomechanical processing, Recrystallization, Shear bands, Twinning

*Corresponding Author. Tel: 765-494-4114, Fax: 765-494-1204, Email: driscol@purdue.edu 


\section{Introduction}

Deformation processing of magnesium $(\mathrm{Mg})$ alloys has received much interest in recent years in view of exploiting their lightweight properties for automotive and other structural applications. Several thermo-mechanical forming routes, including traditional as well as emerging ones, have been applied for processing wrought forms having enhanced mechanical properties over cast counterparts $[1,2,3,4,5]$. All of these processes necessarily involve large-strain deformation, with effective strains in the range of $0.5-1$, for ingot breakdown and refining the microstructure. However, flow localization and cracking continue to pose challenges that limit deformation processing capacity of these alloys $[6,7,8,9]$. In order to overcome these issues, wrought processing is commonly carried out under small incremental strains at elevated temperatures (above $200{ }^{\circ} \mathrm{C}$ ) [1]. Additional annealing treatments are commonly required between the deformation steps for restoring ductility. This requirement for high-temperature processing and intermediate annealing not only contributes to high energy/economic costs, but also limits the scope for microstructure (grain size, texture) control and design.

The poor workability of $\mathrm{Mg}$ and its alloys, long known, is generally attributed to the lack of enough independent slip systems to accommodate the large deformation. More recently, severe flow localization has been identified as the most likely cause for premature failures in forming $[7,8,10]$. In $\mathrm{Mg}$, basal $\langle a\rangle$ slip has the lowest critical resolved shear stress (CRSS), and is therefore the dominant deformation mode. This is particularly true at ambient temperatures $\left(<100{ }^{\circ} \mathrm{C}\right)$ where the CRSS for non-basal slip modes, such as prismatic $\langle a\rangle$ and pyramidal $\langle c+a\rangle$ modes, is $\sim 100$ times that of the basal slip [11,12]. With increasing temperature, CRSS values for non-basal modes decrease significantly, becoming comparable to that of basal slip beyond $200{ }^{\circ} \mathrm{C}[11,12,13]$. The oft-quoted flow transition from brittle to ductile type in the $200-250{ }^{\circ} \mathrm{C}$ temperature range is attributed to the thermal activation of non-basal modes, which provide enough independent slip systems (total of 9, including basal slip) for homogeneous deformation. Under stress states wherein the basal slip is restricted due to geometric constraints, as in compression along the $c$-axis, twinning predominantly contributes to the flow. It has been suggested that the large crystal reorientations associated with twinning induce flow localization and cause overall flow softening 
$[6,10,14,15,16,17]$. At the microstructure level, however, the way the localized flow inside the twins initiates macro-scale localization patterns (e.g., shear bands) is unclear. Dynamic recrystallization (DRX) is another important characteristic of large-strain deformation that contributes to flow softening and grain size refinement, especially at elevated temperatures. The DRX phenomena in wrought processing of Mg have been studied extensively in the context of elucidating microstructure/texture evolution $[3,18,19,20,21]$. The objective of the current study is to understand the possible effects of twinning and DRX on flow localization, and characterize the flow transitions occurring with changes in strain rate and temperature.

Flow localization in Mg-3Al-1Zn alloy (AZ31B) is studied using extrusion-machining (EM) [22]. In EM, a layer of workpiece surface material is removed in the form of a chip by simultaneous cutting and extrusion - in fact, quite analogous to the action of a kitchen peeler. Supplementary Video 1 shows a high-speed video of material flow in EM. The underlying deformation is simple shear. The effective strains $(\varepsilon)$ imposed in the chip are quite large $(\varepsilon \sim 1)$, and the strain rate $(\dot{\varepsilon})$ and temperature $(T)$ in the deformation zone are controllable over a range by adjusting the process parameters. In the current study, $\dot{\varepsilon}$ is varied from $\sim 10$ $/ \mathrm{s}$ to $10^{5} / \mathrm{s}$, and $T$ in the range of $80-300{ }^{\circ} \mathrm{C}$. These conditions encompass those prevailing in conventional wrought processing of $\mathrm{Mg}$ alloys. Detailed microstructural observations of the flow, deformation analysis, and comparison with rolling provide the basis for a model, which qualitatively predicts the susceptibility to flow localization and its dependence on deformation parameters.

\section{Background}

The inhomogeneity of plastic flow in metals is ubiquitous across multiple length scales. Slip bands and Newmann bands (twins) are some manifestations of the micro-scale (grain level) inhomogeneity, while Lüders bands and shear bands are examples of macro-scale localization. This study is concerned with the flow localization in the form of shear bands. Shear bands have been observed in diverse metallic systems and are generally believed to arise from flow-stress softening, due to either adiabatic heating (under dynamic loading conditions) [23] or in-process texture reorientation [24]. An alternative theory suggests dynamic stored energy and DRX as playing a critical role in initiating shear bands [25]. 
A distinct feature of deformation of $\mathrm{Mg}$, when compared with other metals, is the occurrence of inhomogeneous flow at the macro-scale even under relatively low strains $[6,7,26]$. Furthermore, the initial texture and the imposed deformation (stress) state largely determine the deformation mechanisms and have a strong effect on the flow $[16,26]$. The highly inhomogeneous flow in $\mathrm{Mg}$ is indeed expected, given the shortage of independent deformation modes. As noted, basal slip and twinning are the dominant deformation modes at low temperatures $\left(<200{ }^{\circ} \mathrm{C}\right)$, which by themselves are not sufficient to homogeneously accommodate the large strains typical of forming. Localized flow inside twins has been attributed as the origin for this inhomogeneous flow $[6,14,15,16,17,26]$. This phenomenon is best illustrated in rolling of a strongly basal-textured sheet. Since basal slip is geometrically restricted in the "hard" basal texture orientation, the resultant high stresses lead to "contraction" twinning modes (twinning on $\{10 \overline{1} 1\}$ or $\{10 \overline{1} 3\}$ planes) that accommodate compressive strain along the $c$-axis. The crystal reorientation associated with these modes places the twin in a "soft" orientation for favorable basal slip or secondary twinning. Consequently, the twin experience intense localized deformation. In fact, shear strains up to 7 were noted inside the twins [27]. Preferential recrystallization inside the twins, referred to as the twinning-induced dynamic recrystallization (TDRX) $[15,16,17]$, and the signature dark etching contrast [14] are some other indications of the localized flow inside the twins. The incompatibility stresses, which develop across the twin boundaries due to local deformation, also initiate voids and are a cause for premature failure under tension [14]. Under compressive stress states, typical of bulk forming, profuse twinning is believed to contribute to the global flow softening and attendant shear banding [26].

The onset of flow softening or shear banding is generally predicted using load instability $[8,28,29]$ and perturbation $[9,30]$ analyses, assuming a power-law relation for the flow stress $(\sigma)$, given by $\sigma \approx \varepsilon^{n} \dot{\varepsilon}^{m} T^{-v}$, where $n$ is the strain-hardening exponent, $m$ is the strain-rate sensitivity, and $v$ is a thermal-softening parameter. The material properties $(n, m$ and $v)$ are typically treated as constants, independent of the deformation parameters $(\varepsilon, \dot{\varepsilon}$ and $T$ ). However, for $\mathrm{Mg}$ alloys, the effects of deformation parameters on material properties cannot be simply ignored. For example, Fig. 1 illustrates the effect of temperature on $m$ $[3,31,32,33,34,35]$, wherein a 20 -fold increase from $\sim 0.01$ to 0.20 occurs for an increase 


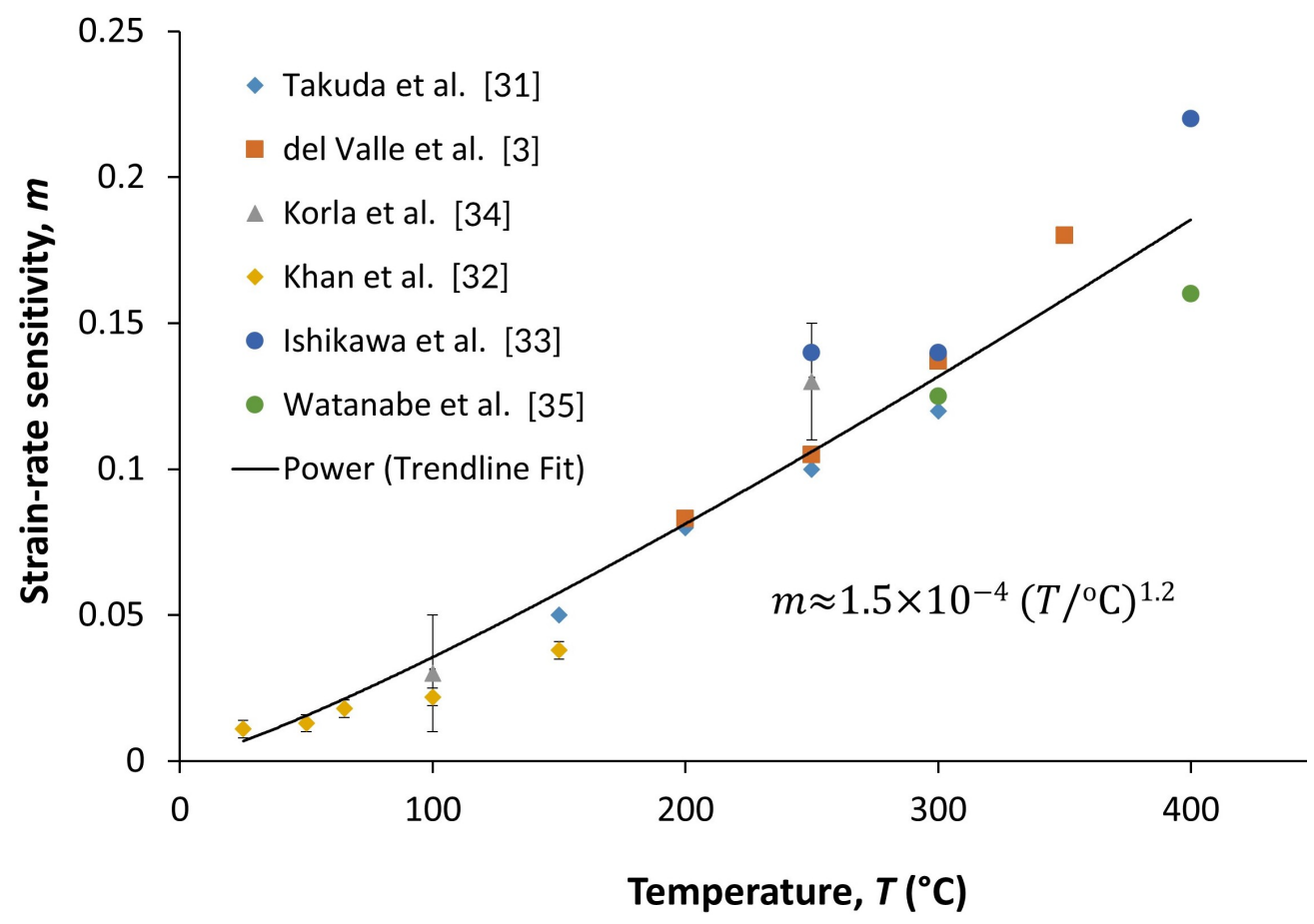

Figure 1: Temperature effect on the strain-rate sensitivity $(m)$ in $\mathrm{Mg}$ AZ31B alloy; $10^{-3} / \mathrm{s} \leq \dot{\varepsilon} \leq 1 / \mathrm{s}$ and $0.05 \leq \varepsilon \leq 0.7$.

in $T$ from $25^{\circ} \mathrm{C}$ to $400{ }^{\circ} \mathrm{C}$, this commonly attributed to the enhanced activity of non-basal slip modes. This study takes into account these dynamic material properties, together with the microstructural effects (twinning), for modeling flow localization.

\section{Experimental}

\subsection{Extrusion-machining (EM)}

Extrusion-machining (EM) is used to impose large-strain deformation in $\mathrm{Mg}$ alloy AZ31B over a range of $\dot{\varepsilon}$ and $T$ in order to characterize flow localization and flow transitions. In EM, a sharp, wedge-shaped cutting tool removes a preset depth (undeformed chip thickness, $t_{o}$ ) of workpiece material in the form of a thin chip/ribbon (see Supplementary Video 1). The stress state is simple shear, as imposed by simultaneous cutting and extrusion. The deformation field in EM has been characterized by in situ high-speed imaging and image analysis using particle image velocimetry (PIV) $[22,36]$. PIV has been traditionally used in fluid mechanics to map the velocity field of fluid flows by tracking motions of particle ensembles. 
(a)

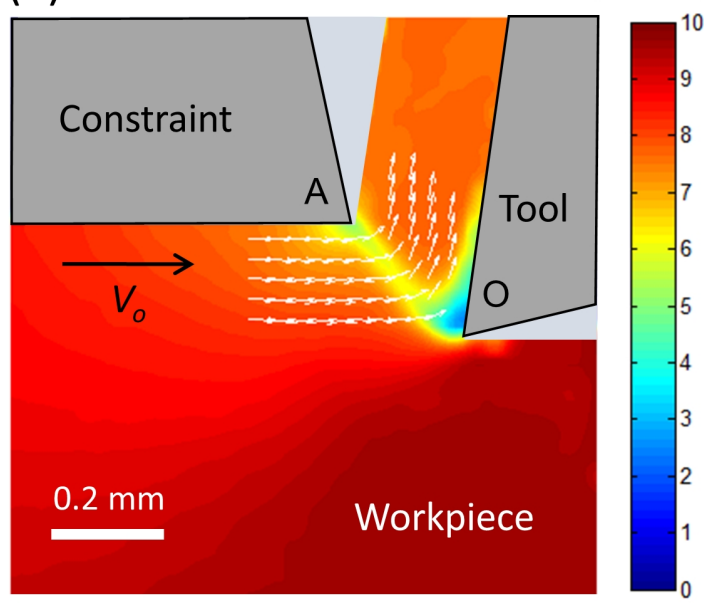

(b)

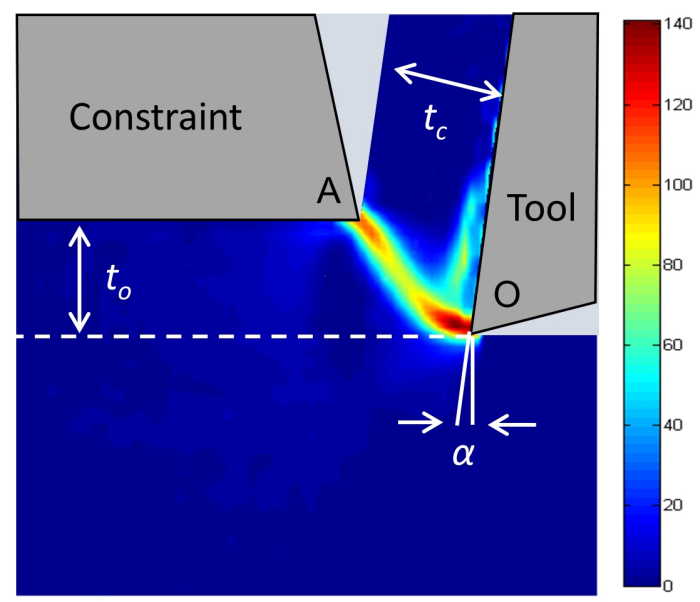

Figure 2: Deformation field in extrusion-machining: (a) velocity and (b) strain-rate fields. Commercially pure lead workpiece, $\alpha=+10^{\circ}, t_{o}=0.2 \mathrm{~mm}, V_{o}=10 \mathrm{~mm} / \mathrm{s}$, and $\lambda=1$.

When using PIV to study deformation, the role of the particles is played by "asperities" roughness features, deliberately introduced by abrasion onto a side of the workpiece surface being imaged. Figure 2a shows the velocity field in EM, with superimposed velocity vectors, as obtained using PIV. The lengths of the vectors represent velocity magnitudes. The corresponding effective strain-rate field is shown in Fig. 2b. The region of intense strain rate, extending from the tool tip to the constraining edge (along OA), is the deformation zone. Note that deformation zone is also the region of maximum velocity change (Fig. 2a). The deformation zone is seen to be reasonably uniform and confined to a thin $(50-100 \mu \mathrm{m})$ region. An analysis of the velocity-gradient tensor in the deformation zone also confirmed the deformation to be simple shear, with the shear direction (i.e., direction of maximum shear strain rate) aligned parallel to the "shear plane", OA [37]. This confinement of deformation and well-defined stress state (simple shear) in EM enables accurate modeling of deformation parameters as a function of process variables.

The ratio $\lambda=t_{c} / t_{o}$ ( $t_{c}$ being the final chip thickness) and the rake angle $(\alpha)$ (see Fig. 2) determine the strain in the chip $(\varepsilon)$. This strain is estimated assuming simple shear along $\mathrm{OA}$ as [22]: 


$$
\varepsilon=\frac{1}{\sqrt{3}}\left(\frac{\lambda}{\cos \alpha}+\frac{1}{\lambda \cos \alpha}-2 \tan \alpha\right)
$$

The strains computed using Eq. 1 have been found to be in good agreement with those directly measured using PIV [22]. For the case in Fig. 2, $\varepsilon$ obtained by integrating along path trajectories in the PIV strain-rate field is $\sim 1.2$, close to $\varepsilon \sim 1$ from Eq. 1 . The hydrostatic pressure $(p)$ in the deformation zone, obtained using slip-line field analysis, increases monotonically with decreasing $\lambda$, reaching a value as high as $\sim 4 k$ ( $k$ being the shear yield stress) at $\lambda=0.5[22]$. Note that these pressure values are much greater than those in torsion $(p \sim 0)$ or plane-strain compression $(p \sim k)$ tests, typically used for large-strain mechanical testing. These high pressures are, in fact, ideal for studying poor-workability alloys, such as Mg, because of the well-known effect of hydrostatic pressure in suppressing damage and failure. Furthermore, simple shear deformation in EM enables studying true material behavior, wherein the geometric effects (e.g., changes in load-bearing area) on the flow are eliminated.

The representative strain rate in the deformation zone is $\dot{\varepsilon} \sim \varepsilon V_{o} / \Delta$ ( $\Delta$ being the deformation zone thickness, $\sim 50-100 \mu \mathrm{m}$ ), and is largely determined by the workpiece surface velocity, $V_{o}$ (Fig. 2). $V_{o}$ can be set practically in the range of $1 \mathrm{~mm} / \mathrm{s}$ to $10 \mathrm{~m} / \mathrm{s}$, giving a five-order variation in $\dot{\varepsilon}$ from $\sim 10 / \mathrm{s}$ to $10^{5} / \mathrm{s}$. Note that these strain rates are much higher than those in conventional material testing methods, and even perhaps higher than in wrought processing (e.g., rolling, extrusion). An obvious consequence of high-rate deformation confined to small volumes, as in EM, is the significant heating due to near-adiabatic conditions that prevail in the deformation zone. The temperature rise associated with this deformation-induced heating can be estimated using a heat transfer model, originally developed for conventional metal cutting [38]. This gives for the average deformation zone temperature $(T)$ :

$$
T=\frac{\beta U_{s}}{\rho c}+T_{o}
$$




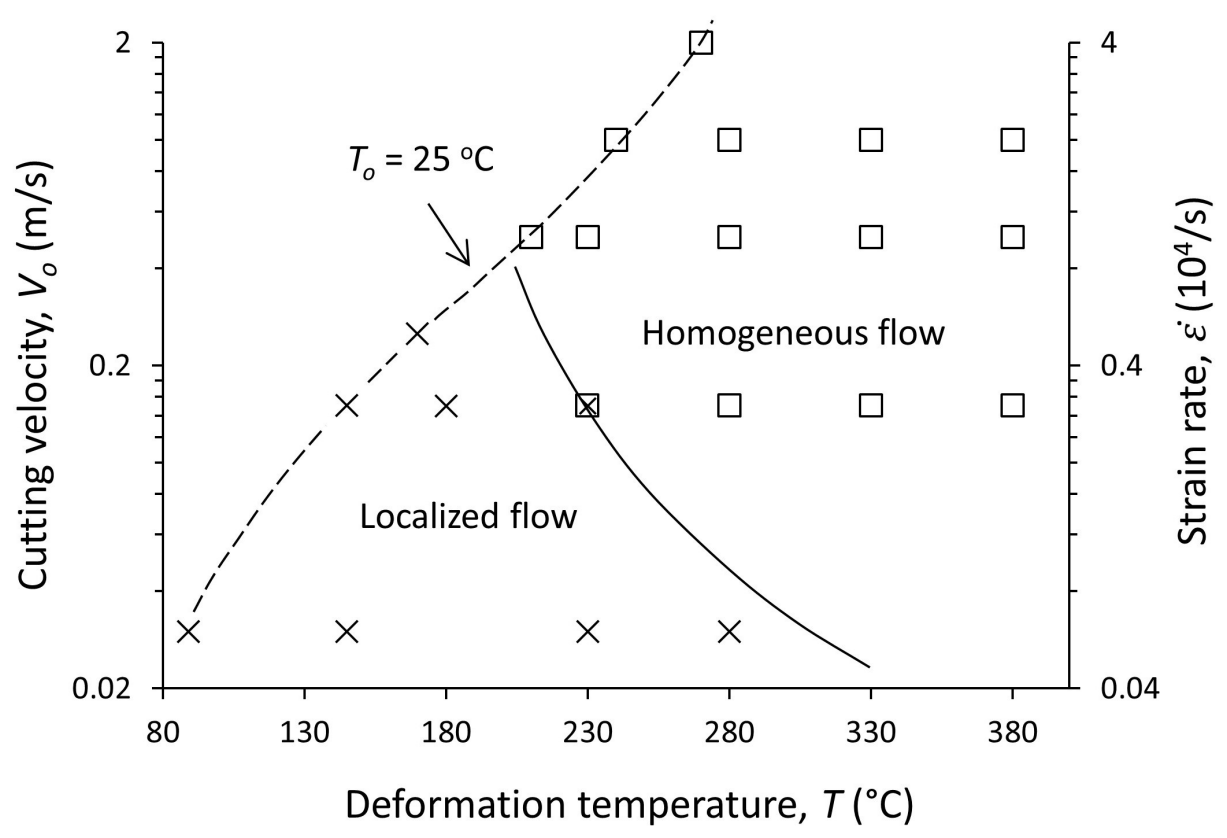

Figure 3: Experimental matrix of $\dot{\varepsilon}-T$ combinations investigated in the present study. The dotted line represents the rate effects on $T$ for $T_{o}=25{ }^{\circ} \mathrm{C}$. $T$ variation at constant $\dot{\varepsilon}$ was achieved by controlling $T_{o}$. The solid line marks the boundary between the regions of localized $(\times)$ and homogeneous $(\square)$ flow.

where $T_{o}$ is initial workpiece temperature, $\beta$ the heat partition coefficient (adiabaticity factor), i.e., the fraction of heat entering the chip, $U_{s}$ the specific shear energy $\left(\mathrm{J} / \mathrm{m}^{3}\right), \rho$ the density, and $c$ the heat capacity. For Mg AZ31B alloy, $\rho$ and $c$ are taken as $1738 \mathrm{~kg} / \mathrm{m}^{3}$ and $1020 \mathrm{~J} / \mathrm{kgK}$, respectively. $U_{s}$ is approximated to first order as $U_{s} \sim 2 / 3\left(F_{c} / t_{o} w\right)$, where $F_{c}$ is the cutting force (force component along $V_{o}$ ) and $w$ is the width of the chip. $\beta$ varies between 0 (static) and 1 (adiabatic) depending on $V_{o}$ (see Ref. [22] for a detailed description).

In the present study, a disk-shaped workpiece was machined out of Mg AZ31B plate and subjected to EM in a rotary configuration on a lathe. The cutting tool and constraint were made of high speed steel. $\varepsilon$ was kept constant at 1.15 in the experiments by fixing $\lambda(0.7)$ and $\alpha\left(5^{\circ}\right)$. $\dot{\varepsilon}$ was varied in the range of $4 \times 10^{2} / \mathrm{s}$ to $10^{5} / \mathrm{s}$ by varying $V_{o}$ from $20 \mathrm{~mm} / \mathrm{s}$ to $5 \mathrm{~m} / \mathrm{s}$. Based on PIV, $\Delta$ was taken as $50 \mu \mathrm{m}$ at all velocities, a reasonable assumption given that $\Delta$ is generally known to decrease with the velocity. Force measurements using a piezoelectric dynamometer, mounted under the tool assembly, showed $U_{s}\left(\sim 4.3 \times 10^{8} \mathrm{~J} / \mathrm{m}^{3}\right)$ to be nearly independent of $V_{o}$ for the velocity range of interest. With increasing $V_{o}, T$ increased sharply initially and gradually saturated at $\sim 280{ }^{\circ} \mathrm{C}$ beyond $2 \mathrm{~m} / \mathrm{s}$. In order to 
separate $\dot{\varepsilon}$ and $T$ effects on the flow, $T$ was independently varied by adjusting $T_{o}$ in the range of $25-250{ }^{\circ} \mathrm{C}$. Figure 3 shows the $\dot{\varepsilon}-T$ matrix designed for this study. Combinations of high $\dot{\varepsilon}$ and low $T$ could not be accessed due to deformation heating effects. The dotted line in the figure represents the rate effects on $T$ for a constant $T_{o}=25{ }^{\circ} \mathrm{C}$ (i.e., no preheating).

\subsection{Rolling}

A small set of flat-rolling experiments was carried out in order to investigate the effects of deformation state on shear banding, for comparison with the EM. The initial workpiece material was $2.8 \mathrm{~mm}$ thick $\mathrm{Mg}$ AZ31B sheet. A fractional thickness reduction $(r)$ of 0.65 was imposed in a single rolling pass in order to achieve a large strain $(\varepsilon=1.21)$, similar to that in EM. $\dot{\varepsilon}$ in rolling is given by:

$$
\dot{\varepsilon}=\frac{2 \pi R W}{60} \frac{1}{L} \varepsilon
$$

where $R$ is the roll radius $(5 \mathrm{~cm}), L$ is the roll contact arc length, given by $L=\sqrt{R r t}$, and $t$ is the initial sheet thickness. The roll rotation rate, $W$, was $35 \mathrm{rpm}$, yielding $\dot{\varepsilon} \sim 20 / \mathrm{s}$. In order to suppress cracking, the samples were pre-heated to $350{ }^{\circ} \mathrm{C}$ before rolling. The rolls were at room temperature. The sample temperature at the roll exit was measured as $\sim 150$ ${ }^{\circ} \mathrm{C}$, which was taken as the deformation temperature.

\subsection{Materials characterization}

Mg AZ31B alloy workpiece was received in plate/sheet form in the annealed condition (O temper) from ThyssenKrupp Materials NA. The workpiece had a hardness of $58 \pm 3 \mathrm{~kg} / \mathrm{mm}^{2}$, grain size of $16 \pm 2 \mu \mathrm{m}$, and a strong basal texture ( 10 mrd texture intensity). Microstructure and micro-hardness of EM and rolled samples were characterized by optical/electron microscopy and Vickers indentation (50-100 g load). For optical microscopy, the samples were mechanically polished and etched for 10-15 seconds using a solution containing 100 $\mathrm{ml}$ ethanol, $10 \mathrm{ml}$ water, $6 \mathrm{~g}$ picric acid and $5 \mathrm{ml}$ acetic acid. For electron backscatter diffraction (EBSD) analysis, the specimens were electropolished using a solution of $125 \mathrm{ml}$ ethanol and $75 \mathrm{ml}$ orthophosphoric acid (3-4 $\mathrm{V}$ at $\sim 0{ }^{\circ} \mathrm{C}$ for $45 \mathrm{~min}$.). EBSD was carried 


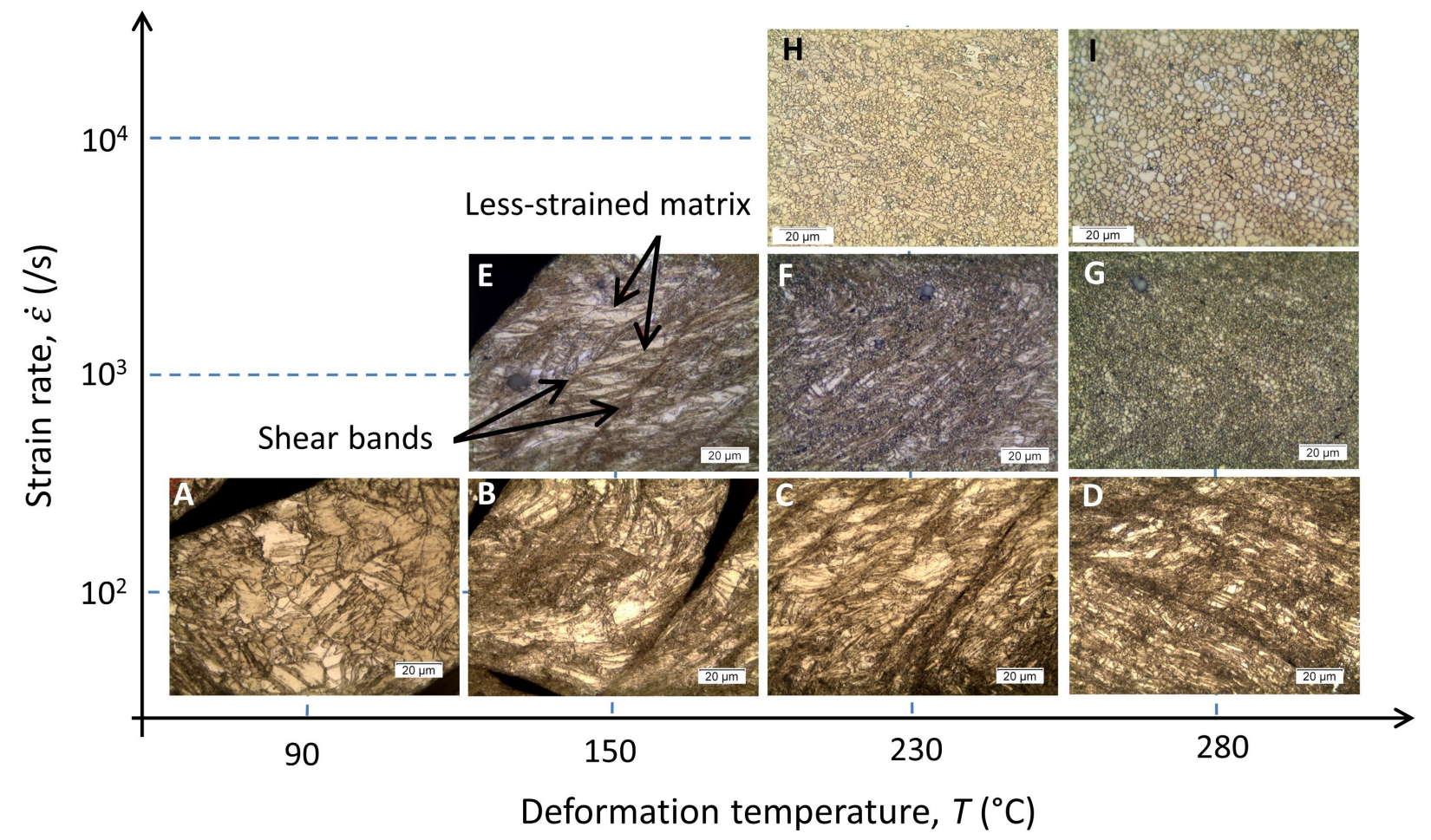

Figure 4: Optical micrographs of the thickness cross-section of the EM $(\varepsilon=1.15)$ samples showing microstructure and flow dependence on $\dot{\varepsilon}$ and $T$.

out in an FEI XL-40 scanning electron microscope (SEM) at $30 \mathrm{kV}$. Transmission electron microscopy (TEM) specimens were prepared by focused ion-beam milling (FIB) or twin-jet electropolishing. The electropolishing was done at $\sim 50 \mathrm{~V}$ and $-20{ }^{\circ} \mathrm{C}$ using a solution of $1 \%$ perchloric acid in ethanol. For FIB, a FEI xT Nova NanoLab Dual Beam FIB/SEM was used. Bright-field TEM images were obtained using an FEI Tecnai microscope operated at $200 \mathrm{kV}$.

\section{Results and Discussion}

\subsection{Flow dependence on $\dot{\varepsilon}$ and $T$}

Figure 4 shows the evolution of plastic flow and microstructure with $\dot{\varepsilon}$ and $T$ under simple shear in EM. Low temperatures at high $\dot{\varepsilon}$ were not possible due to adiabatic heating. $T$ below $100{ }^{\circ} \mathrm{C}$ resulted in severe segmentation/cracking. Figure 5a shows the microstructure of the segmented chip sample A (Fig. 4). The segmentation is likely preceded by the localization of flow. The microstructure is highly inhomogeneous, with strain localized to thin margins 

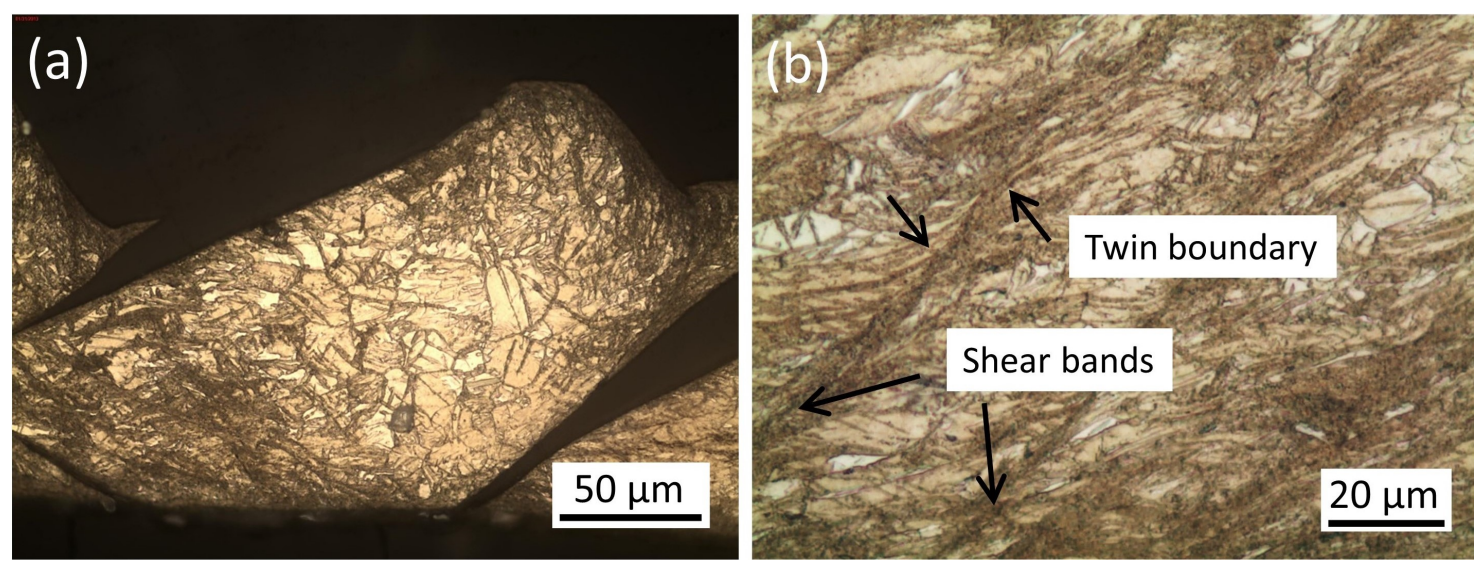

Figure 5: Optical micrographs showing (a) microstructure of fully segmented sample A (Fig. 4) and (b) shear bands and deformation twins in sample C (Fig. 4).

of the segments (dark, unresolvable regions under optical microscope) and less-strained regions inside the segment. Inside the segment, the original grain structure is preserved, and extensive twinning activity is evident.

The extent of segmentation decreases with an increase in $T$ from $150-250{ }^{\circ} \mathrm{C}$ at constant $\dot{\varepsilon}$ $\left(\sim 10^{2} / \mathrm{s}\right)$; see bottom row, Fig. 4 . At $T \sim 230{ }^{\circ} \mathrm{C}$ (C in Fig. 4), the chip is continuous at the macroscopic level. However, the microstructure consists of periodic shear bands and twinned structures in the regions between the bands. Figure 5b shows a higher magnification image of this microstructure highlighting the shear bands and twin boundaries. The dark etching contrast of the bands is due to a concentration of deformation within the bands. The strain inside the bands can be, in fact, deduced by examining the shearing of a twin boundary at the band. The arrows in Fig. 5b mark the displacement of a twin boundary due to localized shear inside the band. The local shear strain, taken as the ratio of this shear displacement to the shear band width, is $\sim 4-6$ (effective strain of 2.3-3.5). This strain is more than twice that of the imposed (macroscopic) strain.

The microstructure of the shear band and that of the twins, resolved using TEM, is shown in Fig. 6. The shear band microstructure (Fig. 6a) is dynamically recrystallized with a grain size of $500 \mathrm{~nm}$ to $1 \mu \mathrm{m}$. This DRX is most likely due to the large strains and associated local heating inside the band. In contrast to the shear bands, the twins show high dislocation density and a non-recovered/recrystallized substructure (Fig. 6b). The streakiness in the 

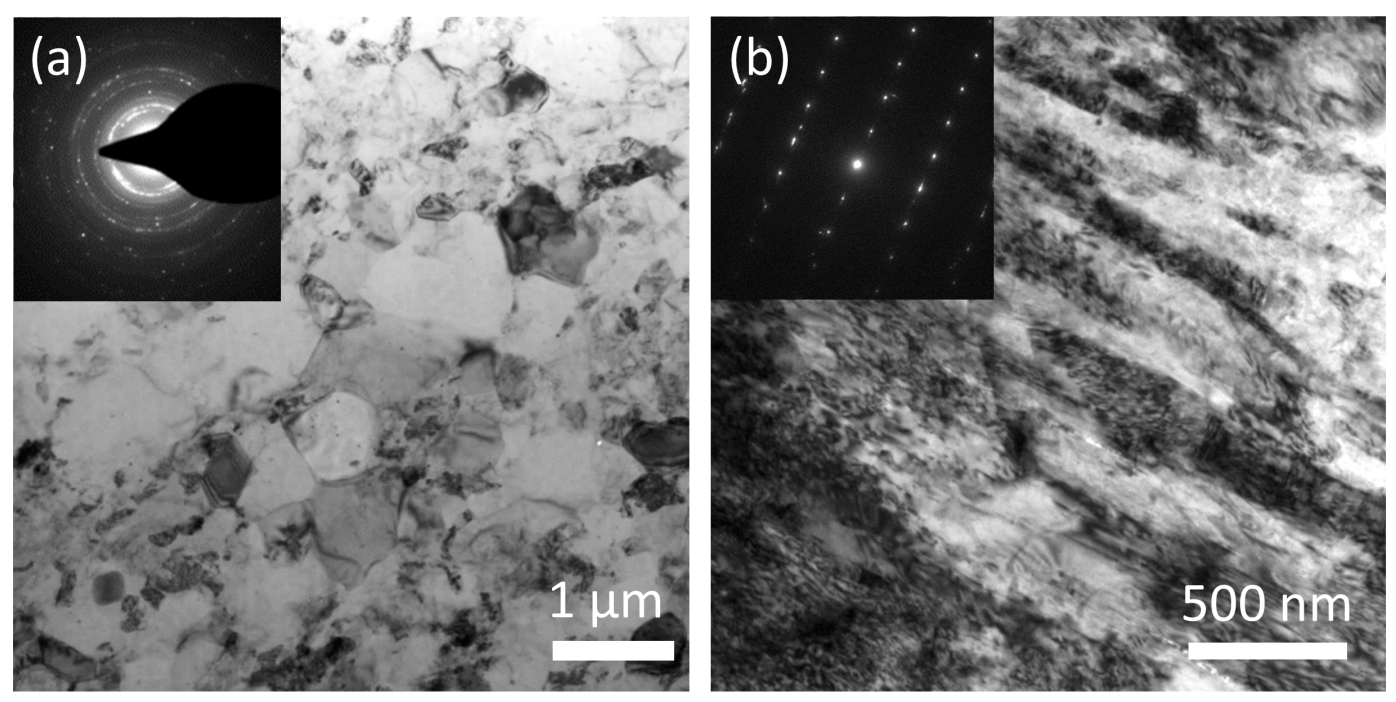

Figure 6: Bright-field TEM images from sample C (Fig. 4) showing (a) DRXed ultrafine microstructure inside the shear band, and (b) heavily dislocated, non-recovered substructure inside the twins.

diffraction pattern (inset, Fig. 6b) is indicative of low-angle cell boundaries. Note that this diffraction pattern is also in strong contrast with the ring-type diffraction pattern from the shear band (inset, Fig. 6a), composed of high-angle grain boundaries. The dense dislocated structure within the twins suggest that, while the deformation is concentrated inside the twins (with respect to the matrix grains), the temperature rise is not sufficiently high to induce any significant recrystallization.

The transition from twinning-dominated flow to dislocation slip and DRX-dominated flow occurs at $\sim 250{ }^{\circ} \mathrm{C}$. Concurrent with this transition, the segmentation and flow localization are also suppressed above $250{ }^{\circ} \mathrm{C}$. Microstructure is nearly uniform (Fig. 4), as it undergoes DRX with a very fine grain size $(1-3 \mu \mathrm{m})$. The twinning activity in the less-strained matrix (regions between the darkly etched bands) also appears to have been suppressed, while fine DRXed grains are now seen inside the shear bands. These observations conclusively point to an increase in the slip activity with temperature.

At a given $T$, increasing $\dot{\varepsilon}$ results in slightly more homogeneous microstructures; see $3^{\text {rd }}$ and $4^{\text {th }}$ columns in Fig. 4. This strain rate dependence of the flow is indicated in Fig. 3, where the solid line marks the approximate boundary between the localized and homogeneous flow. The grain size also increases with $\dot{\varepsilon}$. At the highest $\dot{\varepsilon}$ of $10^{5} / \mathrm{s}$ investigated in this study (not shown), the microstructure was similar to those observed at $10^{4} / \mathrm{s}$ (Fig. 4). 

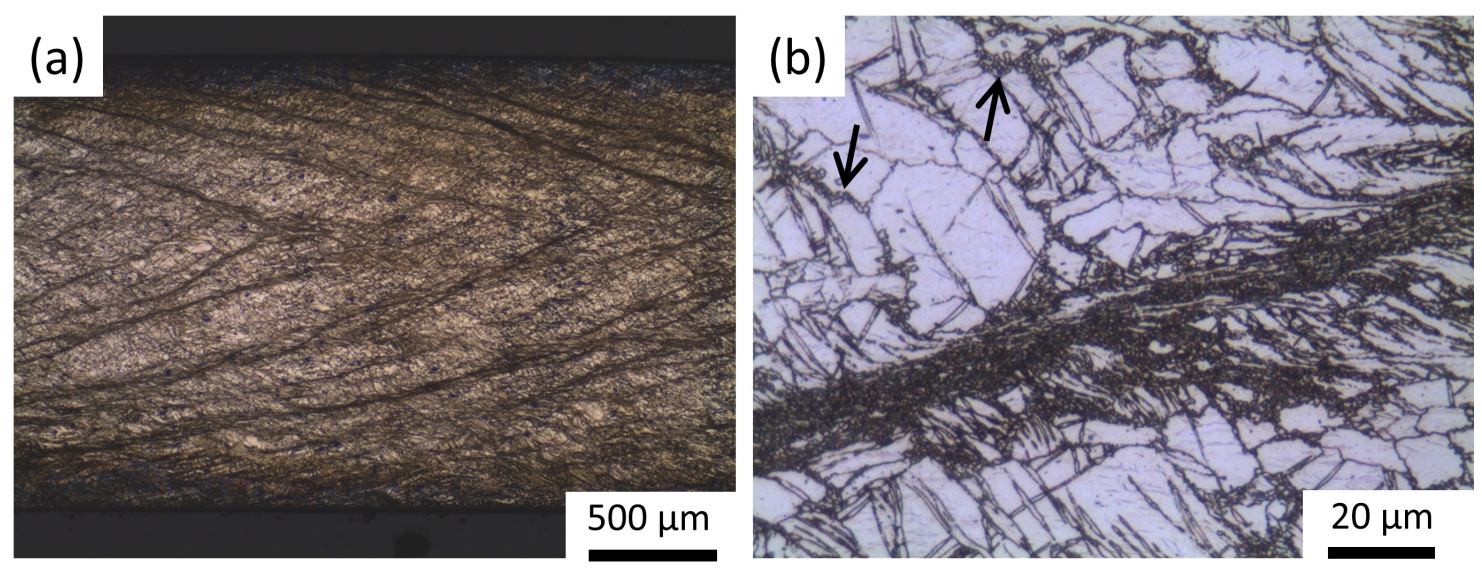

Figure 7: Flow localization in rolling at $\varepsilon=1.21, \dot{\varepsilon}=20 / \mathrm{s}$ and $T=150{ }^{\circ} \mathrm{C}$ : optical micrographs show (a) two sets of shear bands, inclined by $\sim 16^{\circ}$ from the rolling surface, and (b) extremely fine DRXed grains inside the shear band and twins (arrows).

No evidence of flow localization or twinning was observed and the microstructure was fully homogeneous with DRXed grains, albeit with a slightly larger grain size $(\sim 4 \mu \mathrm{m})$. Based on these observations, the flow localization phenomenon in $\mathrm{Mg}$ seems to be more sensitive to $T$ than $\dot{\varepsilon}$. As evident from Fig. 4 , a small change in $T$ of $50{ }^{\circ} \mathrm{C}$ can significantly alter the flow behavior, whereas $\dot{\varepsilon}$ needs to be increased by at least 2 orders of magnitude in order to obtain the same effect.

The sample subjected to rolling deformation at $\dot{\varepsilon}=20 / \mathrm{s}$ and $T \sim 150{ }^{\circ} \mathrm{C}$ shows intense shear banding without segmentation or cracking (Fig. 7). Two sets of shear bands, inclined at $\sim 16^{\circ}$ to the rolling surface, can be seen in Fig. 7a. This angle is significantly different from that of the maximum shear direction of $45^{\circ}$ in rolling. This deviation of the shear band orientation from the maximum shear is likely a result of the strong texture in the starting (as-received) material. The less-strained regions are heavily twinned and very fine DRXed grains are observed inside the shear bands, quite similar to what has been observed in the flow-localized samples produced by EM. The twins in the less-strained regions were also found to comprise of small recrystallized grains (marked by arrows in Fig. 7b). Similarly, the grain boundaries are also decorated with the DRXed grains, suggesting that slip activity outside the shear band is mainly concentrated inside the twins and at grain boundaries. 


\subsection{Microstructural mechanisms}

\subsubsection{Deformation twinning}

Although the flow localization patterns in EM and rolling look similar, it should be noted that the crystallographic orientation of the material entering the deformation zone, as well as the deformation states, in EM and rolling are significantly different. In rolling, for example, the deformation is analogous to plane-strain compression. The initial strong basal texture of the as-received plate restricts the basal slip due to low Schmid factor (SF) (assuming $\pm 5^{\circ}$ tilt of $c$-axis from the ideal basal texture, $\mathrm{SF}=0.09$ ). The material is therefore expected to deform primarily by $\{10 \overline{1} 1\}$ or $\{10 \overline{1} 3\}$ contraction twinning modes at ambient temperatures, considering the CRSS for secondary slip modes is high. This is consistent with the experimental observations of heavily twinned microstructure in Fig. 7. The reorientation of basal planes by $56^{\circ}$ or $64^{\circ}$ as a result of contraction twinning has been previously suggested to initiate the basal slip inside the narrow twins and cause flow localization $[14,15,16]$. The preferential (dynamic) recrystallization inside the twins (Fig. 7b) supports this hypothesis.

In contrast to rolling, the deformation in EM is more complex, especially in the case of Mg. In a prior study [37], the deformation just ahead of the main deformation zone in EM was shown to result in $\{10 \overline{1} 2\}$ (tensile) twinning of the entire workpiece subsurface, thereby completely altering the texture of the material that enters the deformation zone. Note that the initial as-received plate is characterized by a strong basal texture. Therefore, with respect to the EM configuration (Fig. 2), the basal planes were initially aligned parallel to the workpiece side surface (plane of the paper in Fig. 2). However, subsurface $\{10 \overline{1} 2\}$ twinning results in the reorientation of the basal planes parallel to the workpiece (machined) surface. As a result of this texture reorientation, the material that enters the deformation zone is favorably oriented for pyramidal $\langle c+a\rangle$ ( $\mathrm{SF}=0.4)$ slip, when compared to basal $(\mathrm{SF}=0.18)$, prismatic $(\mathrm{SF}=0.12)$ or pyramidal $<a>(\mathrm{SF}=0.15)$ slip. Among twinning modes, tensile twinning is the preferred mode, since the $c$-axis undergoes elongation under simple shear in the deformation zone. Therefore, in EM at low temperatures, Mg is expected to deform primarily by tensile twinning, and to a lesser extent by basal slip.

In order to examine the possibility of flow localization in simple shear due to tensile twinning, the Schmid factors are calculated for basal slip inside the tensile twin and compared 
with that for the matrix. Out of the six tensile twin variants, the two most probable variants (with the highest SF) are considered. The calculations show that the SF for basal slip inside the twins is 0.42 , which is more than twice that for basal slip in the surrounding matrix (SF $=0.18$ ). This suggests that localized flow can indeed occur inside the twins, and perhaps lead to large-scale shear banding. The microstructure inside the twins in EM samples (Fig. 6b) in fact clearly shows dense dislocation substructures and indicates preferential slip activity. It is also likely that at high enough temperatures, the substructures inside the twins undergo DRX. It should be therefore noted that the flow localization under simple shear in EM is caused by tensile twinning reorientation, whereas in compression-type deformation, such as in rolling, the same effect is due to the contraction twinning mode. The current observations therefore show that twinning can be a significant factor leading to flow localization at low $T$, irrespective of the deformation path.

\subsubsection{Dynamic recrystallization}

The transition from localized to homogeneous flow with increasing $T$ is associated with the DRX, as shown in Fig. 4. At low temperatures, the flow is localized to shear bands and deformation in less-strained regions is dominated by twinning. DRX is observed only within the shear bands (Fig. 6a) or inside the twins (Fig. 7a), this being a consequence of the localized slip activity in these regions. With increasing $T$, the flow transforms to homogeneous type. Concurrently, the DRXed grains are observed uniformly over the microstructure, suggesting a distributed slip activity.

The effect of $T$ on DRX was further explored through TEM analysis of the microstructure (Fig. 8). The figure illustrates the microstructural transitions occurring with increasing $\dot{\varepsilon}$ and increasing $T$ (due to deformation heating). At $210{ }^{\circ} \mathrm{C}$, the microstructure is somewhat heterogeneous (Fig. 8a) consisting of apparent dislocation-free regions of $\sim 1 \mu \mathrm{m}$ size (indicated by arrows), surrounded by a matrix of dislocation substructures. This condition signals the beginning of the DRX. This observation is consistent with the reported values of $\sim 220^{\circ} \mathrm{C}$ for DRX under quasi-static deformation rates [18]. Optical microscopy of this sample showed the microstructure to be devoid of any distinct shear bands and also no evidence of twinning, suggesting dislocation slip to be the dominant deformation mechanism. At 230 

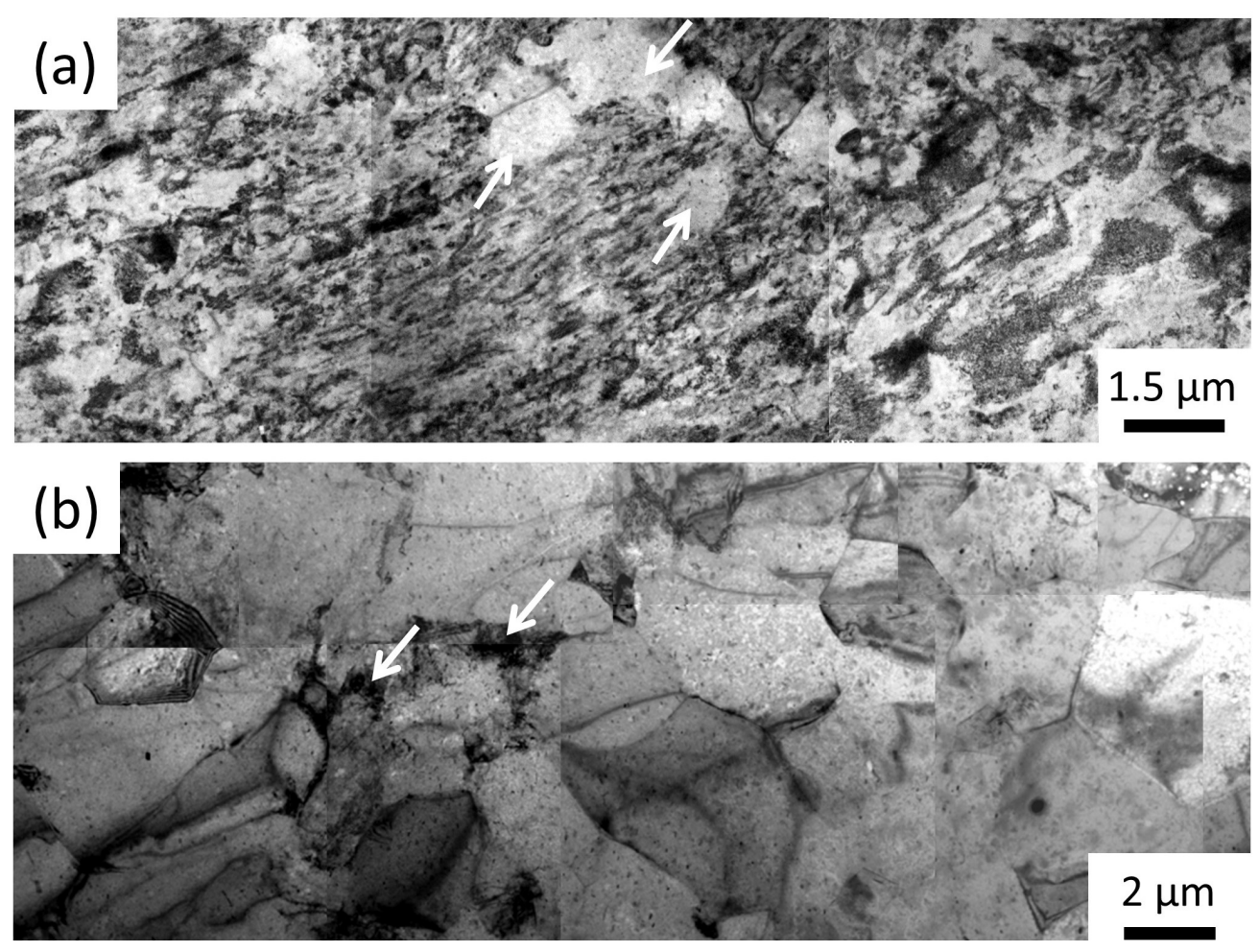

Figure 8: DRX and microstructure evolution with increasing $\dot{\varepsilon}$ (and $T$ ) under EM deformation: (a) $\dot{\varepsilon}=7 \times 10^{3}$ $/ \mathrm{s}, T=210{ }^{\circ} \mathrm{C} ;(\mathrm{b}) \dot{\varepsilon}=1 \times 10^{4} / \mathrm{s}, T=230{ }^{\circ} \mathrm{C}$.

${ }^{\circ} \mathrm{C}$, the microstructure is quite uniform with an almost fully DRXed microstructure having a grain size of $\sim 2-3 \mu \mathrm{m}$ (Fig. 8b). A small fraction of dislocation substructures (arrows, Fig. 8b) is however still present at this $T$. The microstructure, in fact, resembles that of an annealed polycrystalline metal. The gradual transformation of the dislocation substructured microstructure to that of the DRXed type, involving recovery-based cell/grain boundary formation, as observed here, suggests that the recrystallization process is of continuous type (i.e., continuous dynamic recrystallization - CDRX). This is in contrast with the classical mechanism of discontinuous grain nucleation and subsequent growth seen during static recrystallization of deformed microstructures. Moreover, the increased fraction of DRXed region with increased $T$ indicates the thermally enhanced slip activity, as DRX necessarily involves dislocation-mediated flow in Mg.

EBSD analysis (Fig. 9) of the microstructure shown in Fig. 8b (also sample $\mathrm{H}$ in Fig. 4), has provided further insight into the CDRX mechanism and slip activity under simple shear in EM. The poorly indexed regions of the microstructure are colored black in the inverse 
pole figure map (Fig. 9a). These regions likely correspond to the dislocation substructures revealed under the TEM (arrows, Fig. 8b). The pole figures in Fig. 9b show a strong crystallographic texture in the sample with basal planes inclined away from the sample surface by $\sim 40^{\circ}$. In Fig. 9b, CFD, TD and ND are the three orthogonal sample reference directions, namely the chip flow direction (parallel to the cutting tool face in Fig. 2), transverse direction (normal to the plane of paper in Fig. 2) and surface normal direction, respectively. This texture component is referred to as the C-fiber, according to the h.c.p. deformation texture nomenclature, and results from the alignment of basal planes parallel to the shear plane due to basal slip activity. The observed basal plane inclination is, in fact, consistent with the macroscopic shear plane orientation in EM. For EM at $\lambda=0.7$ and $\alpha=5^{\circ}$, the shear plane is rotated from the rake tool face by $\sim 37^{\circ}[37]$. The texture evolution suggests dislocation slip dominated flow and continuous nature of recrystallization, consistent with the TEM observations (Fig. 8). Orientations other than the deformation texture (C-fiber) should have been present, if the recrystallization was of discontinuous type (nucleation and growth). Furthermore, the strong C-fiber texture component indicates that basal slip is the primary slip mode.

The grain-boundary misorientation distribution plot (Fig. 9c) (excluding the poorly indexed regions) shows a large fraction of high-angle grain boundaries. Furthermore, a $30^{\circ}$ misorientation peak is evident from the distribution plot. This is a characteristic feature of CDRX in Mg, where the recrystallized grains attain orientations misoriented from the deformed matrix by $30^{\circ}$ rotation about the $c$-axis [39]. While the texture suggests that basal slip is the dominant slip mode, the formation of high-angle grain boundaries requires cross-slip activity and non-basal dislocations [19, 20]. Therefore, secondary slip modes such as prismatic and pyramidal slip must have also contributed to the plastic flow and formation of the CDRX structure. In fact, basal slip alone cannot provide sufficient number of independent slip systems required for the accommodation of homogeneous deformation. The homogeneous microstructure observed at $T \geq 240{ }^{\circ} \mathrm{C}$ again suggests secondary slip mode contributions, albeit limited, in accommodating the deformation. 


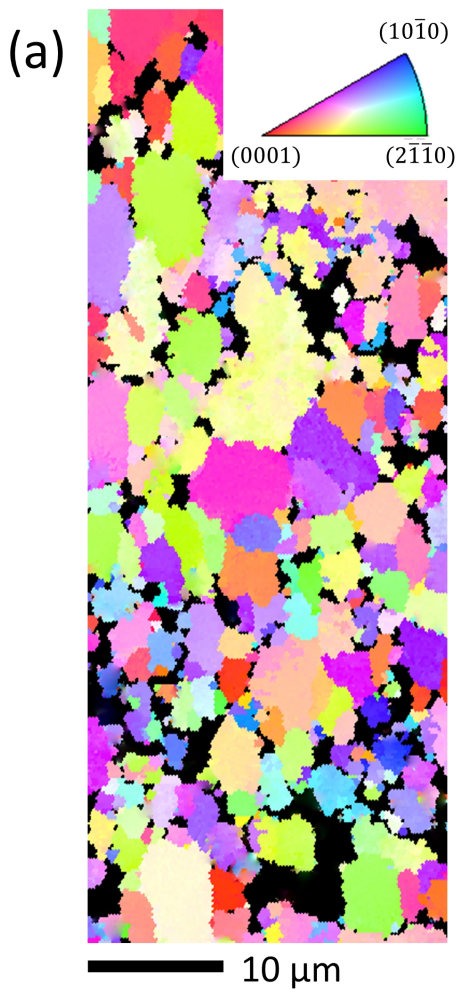

(b)

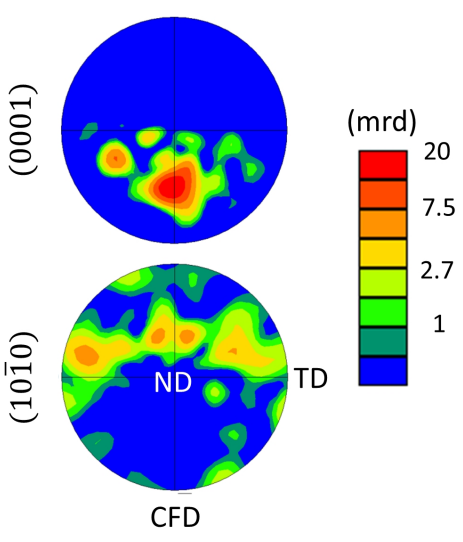

(c)

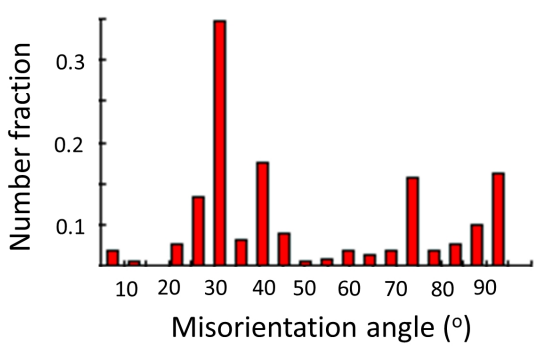

Figure 9: Microstructure and texture in EM at $\dot{\varepsilon}=10^{4} / \mathrm{s}, T=230{ }^{\circ} \mathrm{C}$. (a) The inverse pole figure map taken from the sample surface (CFD-TD plane) showing DRXed grain structure. The black regions represent poorly indexed areas (likely dislocation substructures). (b) Pole figures showing C-fiber texture and inclination of basal planes away from the sample surface by $\sim 40^{\circ}$. (c) Grain-boundary misorientation distribution plot showing a $30^{\circ}$ peak, corresponding to the rotation about the $c$-axis.

\section{Modeling of Flow Localization}

\subsection{Flow localization theory}

The onset of reduction in the flow stress with strain $(d \sigma / d \varepsilon=0)$, while a sufficient condition for the localization of flow, does not always result in severe (catastrophic) shear banding. Superplastic forming is one example, where large levels of deformation can be realized despite significant flow softening. The susceptibility to flow localization is often gauged using the so-called flow localization parameter, $\alpha_{m}$, given by $[28,29,30]$ :

$$
\alpha_{m}=\frac{\partial \ln \dot{\varepsilon}}{\partial \varepsilon}=\frac{1}{\dot{\varepsilon}} \frac{d \dot{\varepsilon}}{d \varepsilon}
$$


Given a weak inhomogeneity, this weakness arising from differences in either geometry (load-bearing area) or material-related factors (e.g., grain size, voids), $\alpha_{m}$ is a measure of the rate of strain concentration in the inhomogeneity compared to its neighboring elements. For simple shear in EM, these elements can be treated as slices (parallel to plane OA, Fig. 2) in the deformation zone. Assuming no shear stress gradient in the direction along the shear plane normal, and that the plastic work is converted to heat with an efficiency determined by the adiabaticity factor, $\beta$ (Eq. 2), $\alpha_{m}$ can be re-written as $[29,40]$ :

$$
\alpha_{m}=-\frac{1}{m}\left\{\frac{1}{\sigma}\left(\frac{\partial \sigma}{\partial \varepsilon}\right)_{T, \dot{\varepsilon}}+\frac{\beta}{\rho c}\left(\frac{\partial \sigma}{\partial T}\right)_{\varepsilon, \dot{\varepsilon}}\right\}
$$

where the strain-rate sensitivity, $m$, is given by $\partial \ln \sigma / \partial \ln \dot{\varepsilon}$ at constant $\varepsilon$ and $T$. The above equation specifies that the tendency for a material to exhibit flow localization depends on the flow-stress softening, and is inversely proportional to $m$. From Eq. 5, it can be seen that any flow-stress softening results in $\alpha_{m}>0$. However, some studies have suggested the occurrence of severe flow localization (of catastrophic type, leading to runaway fracture) only when $\alpha_{m}$ exceeds values of 3-5. This has also been verified experimentally for various deformation geometries, including forging, torsion and cutting [40].

For $\mathrm{Mg}$, the strain-hardening exponent, $n$, is nearly temperature independent up to 200 ${ }^{\circ} \mathrm{C}$ and is $\sim 0.15$ for $\dot{\varepsilon}>10^{-2} / \mathrm{s}$. Above $200{ }^{\circ} \mathrm{C}$, $n$ slightly decreases with $T$, whereas at constant $T$, there is a 2 -fold increase in $n$ from $\sim 0.1$ to 0.2 with increase in $\dot{\varepsilon}$ from $10^{-3}$ to $10^{-1} / \mathrm{s}[31,41]$, and $n$ saturates with further increases in $\dot{\varepsilon}$. Therefore a constant $n=0.15$ is assumed here over a wide range of $\dot{\varepsilon}$ and $T$. Taking a thermal-softening rate $\left(\frac{d \sigma}{d T}\right)_{\varepsilon, \dot{\varepsilon}}=0.75$ $\mathrm{MPa} / \mathrm{K}[33]$ and assuming a constant $m$ of 0.02 (typical of low $T$ deformation for $\mathrm{Mg}$ ), $\alpha_{m}$ is plotted versus $\dot{\varepsilon}$ for $\varepsilon=1.15$ (EM strain in the current study) in Fig. 10 (blue curve). The monotonically increasing $\alpha_{m}$ (i.e., increasing tendency for flow localization) with $\dot{\varepsilon}$ is similar to what is conventionally seen in Ti alloys and steels, which are known for their susceptibility to flow localization at high rates [40]. However, in the present case of $\mathrm{Mg}$, this trend is at variance with the experimental observations (Fig. 4), which reveal diminishing propensity for flow localization at high $\dot{\varepsilon}$ and $T$. 


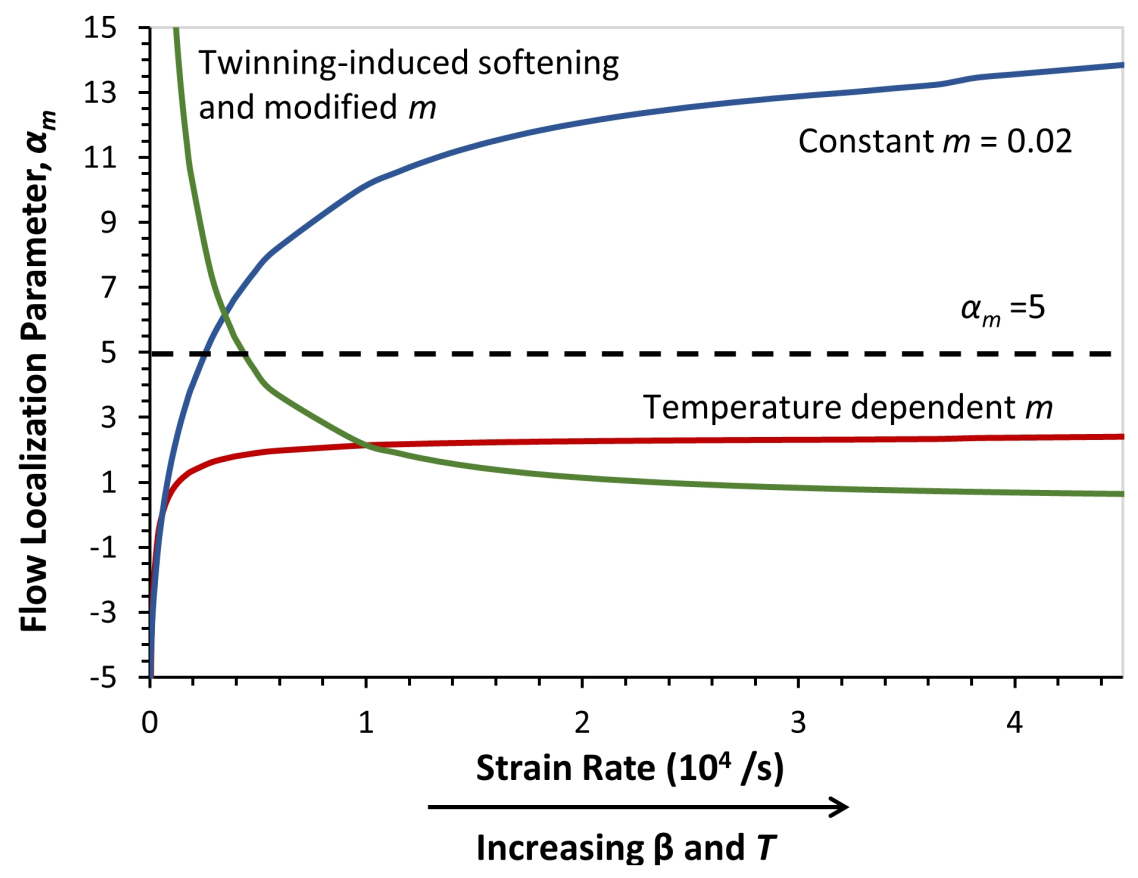

Figure 10: $\alpha_{m}$ vs. $\dot{\varepsilon}$ for $\varepsilon=1.15$ and $T_{o}=25{ }^{\circ} \mathrm{C}$. Blue curve shows the classical flow localization behavior with increasing $\dot{\varepsilon}$ due to thermal softening, assuming constant $m$. Red curve illustrates the flow stabilization effects due to increased $m$ at high $T$. Green curve shows the susceptibility to flow localization at low $\dot{\varepsilon}$ (and $T$ ) due to twinning-induced softening. $\alpha_{m}$ drops below 5 at $\dot{\varepsilon} \sim 5 \times 10^{3} / \mathrm{s}\left(T \sim 190{ }^{\circ} \mathrm{C}\right)$, consistent with the experiments that show homogeneous deformation above this $\dot{\varepsilon}$ and $T$.

\subsection{Incorporating temperature dependence of $m$ and twinning-induced softening}

As shown in Fig. 1, Mg exhibits a sharp increase in $m$ with $T$. Thus, the flow stabilizing effects of $m$ are to be expected (Eq. 5) at high rates due to the deformation heating. Therefore, $\alpha_{m}$ is re-plotted (red curve, Fig. 10) by incorporating the temperature dependence of $m$, as shown in Fig. 1. It can be seen that $\alpha_{m}$ quickly saturates at $\dot{\varepsilon} \sim 4 \times 10^{3} / \mathrm{s}$ (corresponding to $T \sim 175{ }^{\circ} \mathrm{C}$ ) due to the marked increase in $m$.

In order to incorporate the twinning-induced flow softening at low $\dot{\varepsilon}$ and $T$, the continuum is considered as a composite consisting of "soft" (twins) and "hard" (matrix) regions. The flow stress and strain in each region are partitioned using the iso-work (Iso-W) model, developed by Tóth et al. [42]. The Iso-W model assumes that the plastic power is uniform in the continuum: $\dot{\varepsilon} \sigma=\dot{\varepsilon}_{1} \sigma_{1}=\dot{\varepsilon}_{2} \sigma_{2}$, where subscripts 1 and 2 correspond to the matrix and twin fractions, respectively. The flow stress for each region can then be represented using the power-law expression. The strain localizations $\left(r_{i}\right)$ are defined by [42]: 


$$
\begin{gathered}
\dot{\varepsilon}_{1}=r_{1} \dot{\varepsilon}, \quad \varepsilon_{1}=r_{1} \varepsilon, \quad \dot{\varepsilon}_{2}=r_{2} \dot{\varepsilon}, \quad \varepsilon_{2}=r_{2} \varepsilon \\
(1-f) r_{1}+f r_{2}=1
\end{gathered}
$$

where $f$ is the volume fraction of the twins. $\varepsilon$ and $\dot{\varepsilon}$ for the twins will be higher than for the matrix by the softening factor, $S$ :

$$
\frac{\varepsilon_{2}}{\varepsilon_{1}}=\frac{\dot{\varepsilon}_{2}}{\dot{\varepsilon}_{1}}=\frac{r_{2}}{r_{1}}=S
$$

The relative softness of the twins compared to the matrix can be represented by the ratio of Schmid factors of basal slip inside the twins and the matrix, $S=S F_{t} / S F_{m}$, where the $S F_{t}$ and $S F_{m}$ are the Schmid factors for basal slip inside the twin (most favorable variant is considered) and the matrix, respectively. $S F_{t}$ and $S F_{m}$ can be calculated for a given deformation state and initial texture [43]. For EM, $S$ is calculated to be 2.3 (Section 4.2.1). In the case of rolling, where basal slip is completely restricted due to initial basal texture, $S$ is much larger, at $\sim 5$.

Using $\dot{\varepsilon} \sigma=\dot{\varepsilon}_{1} \sigma_{1}, \sigma_{1}=K \varepsilon_{1}^{n}$ ( $K$ being the strength coefficient), and Eq. 6, $\sigma$ is given by:

$$
\sigma=K r_{1}^{n+1} \varepsilon^{n}
$$

where $r_{1}$ is found from Eqs. 7 and 8 as:

$$
r_{1}=\frac{1}{(1-f)+f S}
$$

It is to be noted that $f$ increases with $\varepsilon$. In a similar version of Iso-W model adapted by Barnett for $\mathrm{Mg}$ [14], $f$ is empirically derived as $f=C \varepsilon^{2}$ for $f<0.5$, where $C$ is the twinning-rate constant, which increases with the initial grain size. Similar to $m, C$ also has a temperature dependence since twinning activity decreases with $T$; at high $T$, slip 
becomes the preferred deformation mechanism. Experimental observations in Ref. [14] allow an exponential fit for $C$ for $\mathrm{Mg}$ AZ31B with a grain size of $\sim 10 \mu \mathrm{m}$ : $C=3 \exp (-0.015 T)$, where $T$ is in ${ }^{\circ} \mathrm{C}$. As $\sigma$ is given in terms of $\varepsilon$ (Eq. 9), the first term in Eq. 5 becomes:

$$
\frac{1}{\sigma}\left(\frac{\partial \sigma}{\partial \varepsilon}\right)_{\dot{\varepsilon}, T}=\frac{n}{\varepsilon}-2 \varepsilon C(n+1)(S-1) r_{1}
$$

By substituting $S=2.3$ and $\varepsilon=1.15$ (values for EM in this study), $\alpha_{m}$ (Eq. 5) is plotted again in order to illustrate the effects of twinning-induced softening at low $\dot{\varepsilon}$ and $T$ (green curve, Fig. 10). As opposed to the classical model (Section 5.1), $\alpha_{m}$ now decreases with $T$. The predicted critical deformation rate $\left(\dot{\varepsilon} \sim 5 \times 10^{3} / \mathrm{s}\right)$ and corresponding $T\left(\sim 190{ }^{\circ} \mathrm{C}\right)$ at which $\alpha_{m}$ becomes less than 5 are consistent with the experimental observations (Fig. 4). Note, however, that a lower $\dot{\varepsilon}$ at similar $T$ results in shear banding (Fig. $4,2^{\text {nd }}$ and $3^{\text {rd }}$ columns). This behavior is not captured by the model. Irrespective of $\dot{\varepsilon}$, the increased $m$ with increasing $T$ diffuses the flow despite the existence of "soft spots" in the microstructure [25].

The critical strain at which severe flow localization sets in, $\varepsilon_{l o c}$, is given by:

$$
\varepsilon_{l o c}=\frac{n \varepsilon_{c}}{n-\varepsilon_{c} m \alpha_{m}}
$$

where $\varepsilon_{c}$ is the critical strain corresponding to $\alpha_{m}=0$. Assuming that thermal softening effects are compensated by strengthening effects due to increased $m$, Eq. 5 becomes:

$$
\frac{1}{\sigma}\left(\frac{\partial \sigma}{\partial \varepsilon}\right)_{\dot{\varepsilon}, T}=-\alpha_{m} m
$$

Solving Eqs. 11 and 13 gives $r_{1} \approx 0.9$ for $\alpha_{m}=5$, and $\varepsilon_{l o c}$ can be given in terms of thermo-mechanical and twinning parameters as:

$$
\varepsilon_{l o c}=\frac{\alpha_{m} m+\sqrt{7.2 n(n+1) A+\left(\alpha_{m} m\right)^{2}}}{3.6(n+1) A}
$$




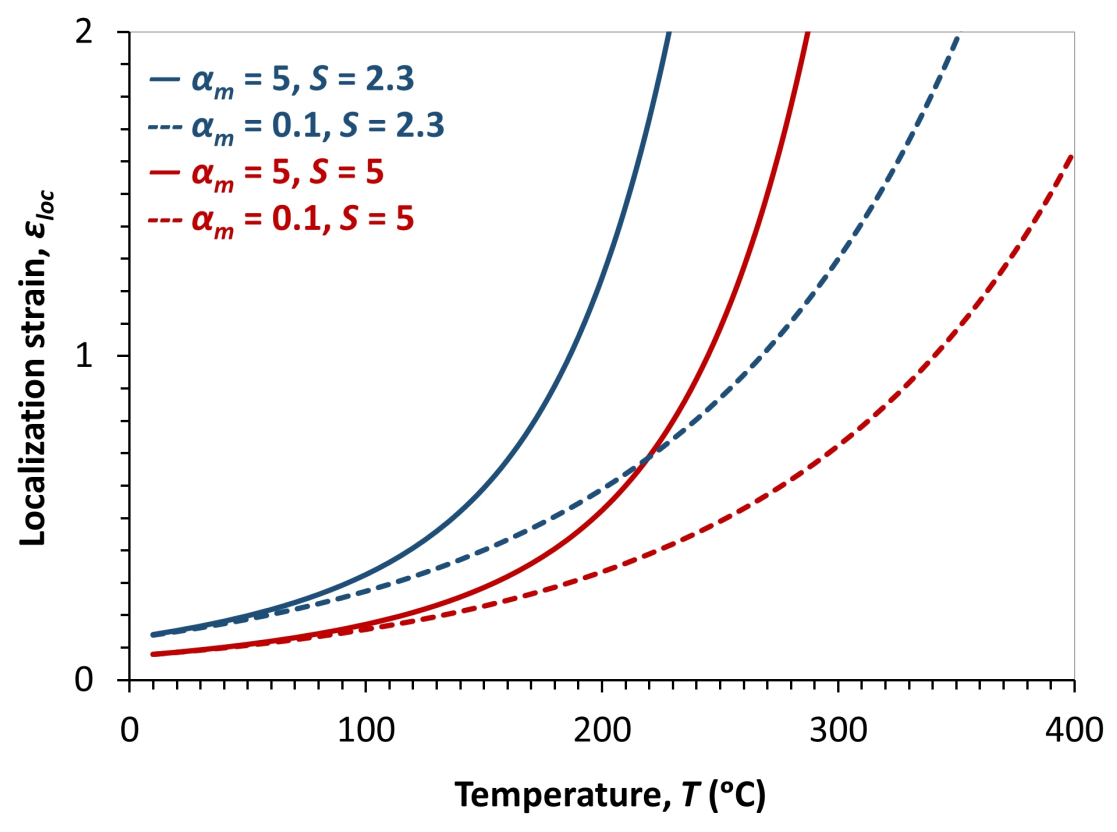

Figure 11: Dependence of $\varepsilon_{l o c}$ on $T$ for different $\alpha_{m}$ and $S$. The criteria of $\alpha_{m}=5$ (solid lines) and $\alpha_{m}=0.1$ (dotted lines) correspond to the critical $T$ required for the suppression of severe flow localization (catastrophic type) and for the full suppression of flow localization, respectively. $S=2.3$ (blue) for EM and $S=5$ (red) for rolling.

where $A=C(S-1)$. Figure 11 shows $\varepsilon_{l o c}$ versus $T$ for different $\alpha_{m}$ and $S$. A high $\varepsilon_{l o c}$ at low $T$ will enable homogeneous deformation and effective grain size refinement in (wrought) deformation processing. Since decreasing $\dot{\varepsilon}$ increases the susceptibility to flow localization in $\mathrm{Mg}, \alpha_{m}=0.1$ criterion can be used for obtaining a conservative limit for $\varepsilon_{l o c}$. This condition will ensure full suppression of flow localization.

Note that highly preferential basal slip inside the twins (high $S$ ) softens the flow stress by decreasing $n$, thereby leading to early flow localization. As a result, $\varepsilon_{l o c}$ decreases with $S$. For example, in the case of EM $(S=2.3, \varepsilon=1.15)$, critical $T$ for suppressing severe flow localization $\left(\alpha_{m} \leq 5\right.$ criterion) is $\sim 190{ }^{\circ} \mathrm{C}$, while temperatures in excess of $240{ }^{\circ} \mathrm{C}$ are required for rolling $(S=5, \varepsilon=1.21)$. Note that for rolling at $150{ }^{\circ} \mathrm{C}$ (current study), $\varepsilon_{l o c}$ is 0.3 , which is quite below the imposed $\varepsilon$ of 1.21 . $T$ should be therefore increased by $\sim 100{ }^{\circ} \mathrm{C}$ in order to obtain a flow without severe shear banding $\left(\alpha_{m} \leq 5\right)$. On the other hand, much higher temperatures are required in order to fully suppress flow localization and achieve microstructures devoid of shear bands ( $\alpha_{m} \leq 0.1$ criterion). Both modeling (Fig. 11) and 
experiments (Fig. 4) consistently show that for $T>280{ }^{\circ} \mathrm{C}$ in EM, and $T>340{ }^{\circ} \mathrm{C}$ in rolling [1], uniformly DRXed microstructures without any evidence of shear banding are realized. The maximum reduction in the current cold-rolling practice of $5-10 \%(\varepsilon=0.06-0.12)$ [1] is also consistent with the model prediction of $\varepsilon_{l o c}=0.09$ at room temperature (Fig. 11).

Unlike the classical flow localization models described earlier in Section 5.1, the present model (Section 5.2) captures the susceptibility to flow localization in $\mathrm{Mg}$ at low $\dot{\varepsilon}$ and $T$ by incorporating the microstructural changes (twinning) and temperature-dependent flow properties of Mg. This modification also eliminates the possibility of thermal softening and flow localization at high $\dot{\varepsilon}$ and $T$. The model is applicable to different deformation geometries; its application to simple shear (EM) and plane-strain compression (rolling) deformation is demonstrated here. Knowing the initial texture of the material a priori, the softening parameter, $S$, can be determined for different deformation geometries. It should be noted that $\varepsilon_{l o c}$ predicted by the model is also influenced by the initial grain size and the alloy composition, as the fitting parameters for $C$ directly depend on these parameters.

Finally, the model becomes invalid at very high $T$, as $\varepsilon_{l o c}$ approaches infinity. While this implies that twinning-induced flow softening is not possible at these temperatures, the material can still fail due to other competing damage mechanisms. In addition, $\varepsilon_{l o c}$ in Fig. 11 is limited to $\varepsilon<2$, as the model is valid only for $f<0.5$.

\section{Summary}

A study has been made of the flow localization behavior in Mg alloy AZ31B under largestrain deformation. The simple shear in extrusion-machining is utilized to impose deformation over a range of strain rates and temperatures and demarcate the regions of localized and homogeneous flow. Twinning-dominated deformation and associated flow-stress softening is found to be responsible for shear banding at low temperatures. The transition in the flow to homogeneous type, with increasing temperature, is accompanied by increased slip activity, dynamic recrystallization and strain-rate sensitivity. At constant deformation temperature, increasing strain rate suppresses shear banding. A phenomenological model is presented for capturing these interactive effects of deformation mechanisms and thermo-mechanical parameters on the flow localization behavior. Based on modeling and experiments, the flow 
transitions in Mg under simple shear can be summarized as:

1. At low temperatures $\left(25-200{ }^{\circ} \mathrm{C}\right)$, the flow is localized in the "soft" twins due to preferential basal slip. The intensity of flow localization depends on the softening term $(S)$ and twinning-rate constant $(C)$. The proposed model predicts the maximum uniform strain by incorporating this twinning-induced flow softening.

2. Intermediate temperatures $\left(200-280{ }^{\circ} \mathrm{C}\right)$ result in increased slip activity, the associated recovery-based (continuous) dynamic recrystallization, and a decreased twinning-rate constant $(C)$. Concurrently, the strain-rate sensitivity is increased. A non-uniform microstructure with diffuse shear bands is observed at these temperatures.

3. At high temperatures $\left(>280^{\circ} \mathrm{C}\right)$, further increases in the strain-rate sensitivity prevent flow localization and compensate for the thermal softening. Twinning is completely suppressed, and fully dynamically recrystallized microstructures are realized.

While the absolute temperature ranges corresponding to these different regimes may vary based on the alloy composition, initial texture/grain size and deformation geometry, the relative effects of temperature on the microstructure evolution and flow localization will likely be similar.

\section{Acknowledgements}

This research was supported in part by U.S. NSF Grants CMMI 1363524 and 1234961, and IIP 1237866. The authors would like to thank Dr. Yang Guo (M4 Sciences LLC.) for assistance with the image analysis.

\section{References}

[1] F. Zarandi, S. Yue, Magnesium sheet: challenges and opportunities, in: F. Czerwinski (Ed.), Magnesium Alloys - Design, Processing and Properties, InTech, Rijeka, Croatia, 2011, pp. 297-320.

[2] S. Seipp, M. F.-X. Wagner, K. Hockauf, I. Schneider, L. W. Meyer, M. Hockauf, Microstructure, crystallographic texture and mechanical properties of the magnesium alloy 
AZ31B after different routes of thermo-mechanical processing, International Journal of Plasticity 35 (2012) 155-166. doi:10.1016/j.ijplas.2012.03.007.

[3] J. del Valle, O. Ruano, Influence of texture on dynamic recrystallization and deformation mechanisms in rolled or ECAPed AZ31 magnesium alloy, Materials Science and Engineering: A 487 (1-2) (2008) 473-480. doi:10.1016/j.msea.2007.11.024.

[4] W. Kim, J. Lee, W. Kim, H. Jeong, H. Jeong, Microstructure and mechanical properties of Mg-Al-Zn alloy sheets severely deformed by asymmetrical rolling, Scripta Materialia 56 (4) (2007) 309-312. doi:10.1016/j.scriptamat.2006.09.034.

[5] Z.-H. Chen, Y.-Q. Cheng, W.-J. Xia, Effect of equal-channel angular rolling pass on microstructure and properties of magnesium alloy sheets, Materials and Manufacturing Processes 22 (1) (2007) 51-56. doi:10.1080/10426910601015907.

[6] M. Barnett, M. Nave, C. Bettles, Deformation microstructures and textures of some cold rolled Mg alloys, Materials Science and Engineering: A 386 (1-2) (2004) 205-211. doi:10.1016/j.msea.2004.07.030.

[7] R. B. Figueiredo, P. R. Cetlin, T. G. Langdon, The processing of difficult-to-work alloys by ECAP with an emphasis on magnesium alloys, Acta Materialia 55 (14) (2007) 47694779. doi:10.1016/j. actamat.2007.04.043.

[8] F. Kang, J. T. Wang, Y. Peng, Deformation and fracture during equal channel angular pressing of AZ31 magnesium alloy, Materials Science and Engineering: A 487 (1-2) (2008) 68-73. doi:10.1016/j.msea.2007.09.063.

[9] R. Lapovok, L. S. Tóth, A. Molinari, Y. Estrin, Strain localisation patterns under equalchannel angular pressing, Journal of the Mechanics and Physics of Solids 57 (1) (2009) 122-136. doi:10.1016/j.jmps.2008.09.012.

[10] P. Changizian, A. Zarei-Hanzaki, M. Ghambari, A. Imandoust, Flow localization during severe plastic deformation of AZ81 magnesium alloy: micro-shear banding phenomenon, Materials Science and Engineering: A 582 (2013) 8-14. doi:10.1016/j.msea.2013. 05.069. 
[11] R. Reed-Hill, W. Robertson, The crystallographic characteristics of fracture in magnesium single crystals, Acta Metallurgica 5 (12) (1957) 728-737. doi:10.1016/ 0001-6160(57)90075-5.

[12] T. Obara, H. Yoshinga, S. Morozumi, $\{11 \overline{2} 2\}<\overline{1} \overline{1} 23>$ slip system in magnesium, Acta Metallurgica 21 (7) (1973) 845-853. doi :10.1016/0001-6160(73)90141-7.

[13] P. W. Flynn, J. Mote, J. E. Dorn, On the thermally activated mechanism of prismatic slip in magnesium single crystals, Transactions of the Metallurgical Society of AIME 221 (6) (1961) 1148-1154.

[14] M. Barnett, Twinning and the ductility of magnesium alloys, Materials Science and Engineering: A 464 (1-2) (2007) 8-16. doi:10.1016/j.msea.2007.02.109.

[15] T. Al-Samman, K. D. Molodov, D. A. Molodov, G. Gottstein, S. Suwas, Softening and dynamic recrystallization in magnesium single crystals during c-axis compression, Acta Materialia 60 (2) (2012) 537-545. doi:10.1016/j.actamat.2011.10.013.

[16] Y. Chun, C. Davies, Texture effects on development of shear bands in rolled AZ31 alloy, Materials Science and Engineering: A 556 (2012) 253-259. doi:10.1016/j .msea.2012. 06.083.

[17] K. D. Molodov, T. Al-Samman, D. A. Molodov, G. Gottstein, Mechanisms of exceptional ductility of magnesium single crystal during deformation at room temperature: Multiple twinning and dynamic recrystallization, Acta Materialia 76 (2014) 314-330. doi:10. $1016 / j$. actamat . 2014.04.066.

[18] A. Galiyev, R. Kaibyshev, G. Gottstein, Correlation of plastic deformation and dynamic recrystallization in magnesium alloy ZK60, Acta Materialia 49 (7) (2001) 1199-1207. doi : 10.1016/S1359-6454(01)00020-9.

[19] O. Sitdikov, R. Kaibyshev, Dynamic recrystallization in pure magnesium., Materials Transactions 42 (9) (2001) 1928-1937. doi:10.2320/matertrans.42.1928. 
[20] M. Myshlyaev, H. McQueen, A. Mwembela, E. Konopleva, Twinning, dynamic recovery and recrystallization in hot worked Mg-Al-Zn alloy, Materials Science and Engineering: A 337 (1-2) (2002) 121-133. doi:10.1016/S0921-5093(02)00007-2.

[21] E. Martin, J. J. Jonas, Evolution of microstructure and microtexture during the hot deformation of Mg-3\% Al, Acta Materialia 58 (12) (2010) 4253-4266. doi:10.1016/j. actamat.2010.04.017.

[22] M. Efe, W. Moscoso, K. P. Trumble, W. Dale Compton, S. Chandrasekar, Mechanics of large strain extrusion machining and application to deformation processing of magnesium alloys, Acta Materialia 60 (5) (2012) 2031-2042. doi:10.1016/j .actamat. 2012. 01.018.

[23] C. Zener, J. H. Hollomon, Effect of strain rate upon plastic flow of steel, Journal of Applied Physics 15 (1) (1944) 22. doi:10.1063/1.1707363.

[24] I. L. Dillamore, J. G. Roberts, A. C. Bush, Occurrence of shear bands in heavily rolled cubic metals, Metal Science 13 (2) (1979) 73-77. doi:10.1179/msc.1979.13.2.73.

[25] D. Rittel, Z. G. Wang, M. Merzer, Adiabatic shear failure and dynamic stored energy of cold work, Physical Review Letters 96 (7) (2006) 075502. doi:10.1103/PhysRevLett. 96.075502 .

[26] L. Jiang, J. Jonas, R. Mishra, A. Luo, A. Sachdev, S. Godet, Twinning and texture development in two $\mathrm{Mg}$ alloys subjected to loading along three different strain paths, Acta Materialia 55 (11) (2007) 3899-3910. doi:10.1016/j .actamat.2007.03.006.

[27] R. Reed-Hill, W. Hartt, Shear accommodation kinking at second order twins in magnesium, Transactions of the Metallurgical Society of AIME 242 (10) (1968) 1127.

[28] J. Jonas, R. Holt, C. Coleman, Plastic stability in tension and compression, Acta Metallurgica 24 (10) (1976) 911-918. doi:10.1016/0001-6160(76)90039-0.

[29] S. Semiatin, M. Staker, J. Jonas, Plastic instability and flow localization in shear at high rates of deformation, Acta Metallurgica 32 (9) (1984) 1347-1354. doi:10.1016/ 0001-6160 (84) 90080-4. 
[30] Y. Bai, Thermo-plastic instability in simple shear, Journal of the Mechanics and Physics of Solids 30 (4) (1982) 195-207. doi :10.1016/0022-5096(82)90029-1.

[31] H. Takuda, T. Morishita, T. Kinoshita, N. Shirakawa, Modelling of formula for flow stress of a magnesium alloy AZ31 sheet at elevated temperatures, Journal of Materials Processing Technology 164-165 (2005) 1258-1262. doi:10.1016/j.jmatprotec. 2005. 02.034.

[32] A. S. Khan, A. Pandey, T. Gnäupel-Herold, R. K. Mishra, Mechanical response and texture evolution of AZ31 alloy at large strains for different strain rates and temperatures, International Journal of Plasticity 27 (5) (2011) 688-706. doi:10.1016/j.ijplas. 2010.08 .009 .

[33] K. Ishikawa, H. Watanabe, T. Mukai, High temperature compressive properties over a wide range of strain rates in an AZ31 magnesium alloy, Journal of Materials Science 40 (7) (2005) 1577-1582. doi:10.1007/s10853-005-0656-1.

[34] R. Korla, A. H. Chokshi, Strain-rate sensitivity and microstructural evolution in a MgAl-Zn alloy, Scripta Materialia 63 (9) (2010) 913-916. doi:10.1016/j.scriptamat. 2010.06 .047 .

[35] H. Watanabe, K. Ishikawa, Effect of texture on high temperature deformation behavior at high strain rates in a Mg-3Al-1Zn alloy, Materials Science and Engineering: A 523 (12) (2009) 304-311. doi:10.1016/j.msea.2009.06.019.

[36] Y. Guo, M. Efe, W. Moscoso, D. Sagapuram, K. Trumble, S. Chandrasekar, Deformation field in large-strain extrusion machining and implications for deformation processing, Scripta Materialia 66 (5) (2012) 235-238. doi:10.1016/j.scriptamat.2011.10.045.

[37] D. Sagapuram, M. Efe, W. Moscoso, S. Chandrasekar, K. P. Trumble, Controlling texture in magnesium alloy sheet by shear-based deformation processing, Acta Materialia 61 (18) (2013) 6843-6856. doi:10.1016/j.actamat.2013.07.063.

[38] J. H. Weiner, Shear-plane temperature distribution in orthogonal cutting, Transactions of the American Society of Mechanical Engineers 77 (8) (1955) 1331-1338. 
[39] J. A. del Valle, M. T. Pérez-Prado, O. A. Ruano, Deformation mechanisms responsible for the high ductility in a Mg AZ31 alloy analyzed by electron backscattered diffraction, Metallurgical and Materials Transactions A 36 (6) (2005) 1427-1438. doi:10.1007/ s11661-005-0235-8.

[40] S. L. Semiatin, J. J. Jonas, Formability and Workability of Metals: Plastic Instability and Flow Localization, American Society for Metals, Metals Park, OH, 1984.

[41] S. R. Agnew, O. Duygulu, Plastic anisotropy and the role of non-basal slip in magnesium alloy AZ31B, International Journal of Plasticity 21 (6) (2005) 1161-1193. doi:10.1016/ j.ijplas.2004.05.018.

[42] L. S. Tóth, A. Molinari, O. Bouaziz, Effective strain rate sensitivity of two phase materials, Materials Science and Engineering: A 524 (1-2) (2009) 186-192. doi: $10.1016 / j$.msea.2009.06.041.

[43] X.-L. Nan, H.-Y. Wang, L. Zhang, J.-B. Li, Q.-C. Jiang, Calculation of Schmid factors in magnesium: Analysis of deformation behaviors, Scripta Materialia 67 (5) (2012) 443-446. doi:10.1016/j.scriptamat.2012.05.042. 